\title{
Diseño gráfico
}

\section{Daniel TENA PARERA \\ Diseño gráfico publicitario}

Editorial Síntesis, Madrid, 2017, 304 pp.

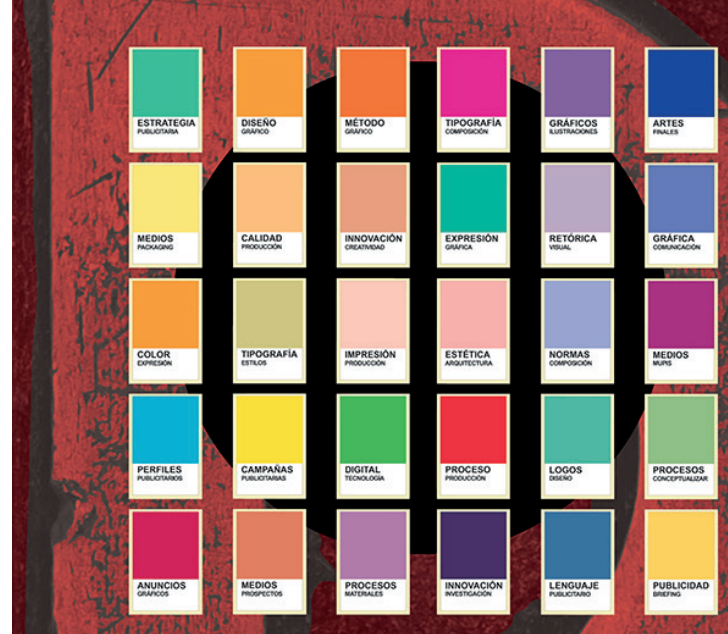

Diseño épáfico publicitario

Daniєl Tena Parera

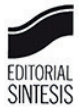

La ressenya bibliogràfica que a continuació es presenta fa referència a la darrera publicació del professor de la Universitat Autònoma de Barcelona, Daniel Tena Parera. El contingut d'aquesta obra aborda amb rigor i solvència la temàtica del disseny gràfic i la direcció d'art en publicitat. De la lectura de les seves pàgines se'n desprèn coneixement i didàctica de la disciplina, la qual cosa fa que esdevingui un valuós i recomanable manual de consulta concebut especialment per a estudiants de grau i professionals que es trobin implicats en projectes de gràfica publicitària.

\section{Paraules clau}

Disseny gràfic; publicitat; gràfica publicitària; direcció d'art; producció gràfica

\section{Advertising graphic design}

Graphic design and advertising art direction. Editorial Síntesis, Madrid, 2017, 304 pp.

The present bibliographic review goes remitted to the last publication of the professor of the Autonomous University of Barcelona, Daniel Tena Parera. The content tackles with rigour and depth the subjects of graphic design and direction of art in advertising. Reading his pages will find knowledge and didactic of the discipline. For this reason, it turns into a valuable and recommended manual of reference especially for students of degree and professionals that find involved in projects of graphic advertising.

Keywords

Graphic design, advertising; advertising graphic; art direction; graphic production 
La reconeguda editorial Síntesis, especialitzada en l'edició de llibres acadèmics i tècnics, ha incorporat al seu catàleg un nou títol: Diseño gráfico publicitario. Aquesta obra escrita per Daniel Tena Parera, Tercera línia posar: Professor Titular de la Universitat Autònoma de Barcelona, s'ha concebut com un excel-lent manual d'estudi i consulta indicat per a estudiants universitaris o de cicles formatius de grau superior, però també per a dissenyadors i docents que vulguin millorar els seus coneixements i competències professionals a través d'aprofundir en la fonamentació teòrica de la publicitat gràfica i la direcció d'art. Al cap i a la $\mathrm{fi}$, es tracta d'un manual que s'origina en base al treball rigorós de recerca desenvolupat per l'autor i que, sens dubte, pot ajudar a interioritzar criteris d'anàlisi a fi d'abordar amb solvència la pràctica professional del disseny gràfic publicitari.

De primer antuvi, el pròleg exposa de forma clara, sintètica i eloqüent el que esdevindrà el principi subjacent de l'obra: quan la raó guia el discurs de la intuïció. Raó i intuïció en tant que dues expressions humanes i interdependents de la pròpia intel-ligència visual; dues formes d'aproximació al coneixement. De fet, tal i com afirmava l'eminent José María Ricarte, la creativitat és una atzarosa (inusual) combinació de lògica i d'intuïció.

Enmig d'un ecosistema visual saturat d'estímuls en el qual es fomenta una actitud essencialment reactiva sobre els públics del disseny, la intuïció i l'emoció esdevenen facultats cognitives implicades en la major part dels processos de decisió. En aquest context, on una de les principals preocupacions se circumscriu habitualment a conèixer el què (l'efecte resultant) i s'obvia la profunditat del per què (la causa originària), abordar l'anàlisi de la causalitat dels efectes del disseny gràfic fa d'aquesta publicació una referència conceptualment atípica. D'acord amb això, l'obra s'endinsa en la disciplina del disseny gràfic publicitari -el producte de la qual sempre és sotmès al veredicte subjectiu, directe $\mathrm{i}$ immediat de la intuïció- però des d'una perspectiva premeditadament racional i lògica. En si mateix, el treball s'inscriu en un metallenguatge atès que el seu discurs s'articula a l'entorn d'un llenguatge escrit amb el propòsit de descriure els fonaments teòrics d'un altre llenguatge: la gràfica publicitària. Per tant, que ningú hi busqui, en el decurs de les seves pàgines, un receptari pràctic de disseny ni un mostrari professional de campanyes amb peces gràfiques publicitàries.

Durant molts anys, les rutines productives associades a la creació gràfica dels projectes han estat regides per la mera intuïció; una intuïció, val a dir, bastida mitjançant la seguretat que atorga l'experiència professional i que, tanmateix, ha esdevingut necessària i útil quan la formació acadèmica $\mathrm{i}$ en recerca era escassa o residual. En aquest sentit, Diseño gráfico publicitario es presenta com una contribució més al coneixement científic de la disciplina que, tal vegada, és la conseqüència natural d'anys de reflexió i investigació de l'autor a fi de copsar -més enllà de la mera intuïció- la lògica íntima del disseny gràfic. En conseqüència, més enllà dels protocols establerts per la pròpia experiència, la present publicació s'ha d'entendre com un valuós instrument gràcies al qual sigui possible fonamentar i articular propostes solvents de disseny gràfic.

El cos del llibre queda configurat per dotze capítols agrupats en quatre parts temàtiques. En aquest sentit, és interessant assenyalar que al final de cada capítol s'inclouen activitats didàctiques a fi de reflexionar i treballar els continguts teòrics.

El plantejament de la primera part té un propòsit marcadament introductori dins de la qual es despleguen els tres primers capítols que fan una contextualització del disseny gràfic publicitari. En particular, s'aborden els subjectes i la naturalesa de l'objecte d'estudi així com qüestions relacionades amb l'estratègia i l'expressió publicitàries. En un context on es pretén validar l'eficiència del missatge gràfic, és imprescindible que sempre hi hagi una complicitat entre l'estratègia comunicativa i la formal.

La segona part és força genuïna i singular ateses les aportacions que es realitzen des d'un enfoc eminentment acadèmic. Des d'aquest punt de vista, s'observa una aproximació a la teorització del disseny gràfic publicitari. Una fonamentació teòrica que queda adequadament sostinguda per una base conceptual i metodològica. No obstant això, la dimensió estratègica esdevé nuclear en aquest punt del discurs atès que posa de manifest un axioma recurrent: sense estratègia no s'entén l'activitat del disseny gràfic.

A continuació el tercer apartat se circumscriu a la descripció dels elements del llenguatge visual que intervenen en la formulació del missatge; en termes generals, s'aborden aquelles característiques tècniques que configuren l'estructura del discurs visual: l'espai gràfic, el color, la tipografia i les imatges o gràfics.

Finalment, la quarta part desenvolupa aspectes vinculats a la realització de les arts finals, ja sigui des dels àmbits de la publigrafia, identitat corporativa, anuncis, packaging o web sites. Segons això, el llibre no és només un tractat sobre disseny 
101

Jordi Colet Ruz gràfic publicitari; és també una guia de producció gràfica concebuda per a l'oportuna preparació de les peces publicitàries segons els diferents tipus de suports. Aquest fet posa de manifest l'evident maridatge entre ambdues activitats.

Així mateix, convé assenyalar que, a banda de l'edició en paper, el contingut del llibre enllaça amb uns annexos publicats a la pàgina web de l'editorial. Són materials d'estudi degudament referenciats en el text que permeten aprofundir sobre qüestions puntuals com: la investigació científica en l'àmbit del disseny gràfic, la classificació dels impresos, la percepció gràfica, l'anàlisi multivariable de l'Estat Estètic, les tipologies d'imatge i els processos de producció gràfica. Sens dubte, un excel-lent complement per a una publicació necessària i amb vocació referencial en el seu àmbit. 
